\title{
Childhood Focal Epilepsies
}

\author{
Wael hayel khreisat \\ Pediatric neurologist,Queen Rania hospital for children, \\ King Hussein medical center \\ Royal medical services, Amman, Jordan
}

\begin{abstract}
Objective: The present study was done in order to obtain a baseline profile of childhood focal epilepsies

Patient and methods: Subjects included in this study were children suffering from focal epilepsy with age above $2 \mathrm{y}$. They were attending pediatric neurology clinic in Queen Rania Hospital for children in Jordan. The study included 112 children with ages ranging from 2-14 years. The following data were obtained: age, sex, detailed of seizures type, age at first unprovoked seizure, family history of seizure disorders, history and type of febrile seizures, etiological factors, socioeconomic class, history of consanguinity, additional neuro -impairment,

Electroencephalography and brain imaging finding and the use of antiepileptic drugs, the results were recorded for further study.
\end{abstract}

Results: A total of 112 consecutive cases of focal epilepsy were enrolled, 59 were male. The commonest partial seizure recorded was simple partial type $52(46.4 \%)$ while simple partial with secondary generalization had $17(16.9 \%)$ and complex partial seizure formed $36.8 \%$. ), In partial onset seizures the peak age was between 11-14 years and complex partial seizures plateau was seen between ages 6-10 years. Twenty six (23.2\%) patients reported a family history of epilepsy, $91 \%$ of low socioeconomic class $.11 .5 \%$ of cases have history of febrile seizures, idiopathic epilepsy was $53.5 \%$. In most of epileptic patients have accessory neurological impairment, the most common were learning difficulties Electroencephalography was normal in $20.4 \%$, monotherapy was used in $68.8 \%$

Conclusion: the pattern of focal epilepsies in our country do not differ from that of developed countries, further population -based epidemiological research is indicated to confirm the prevalence of seizure disorders in this locality

Keywords: partial seizure, complex partial seizure

\section{Introduction:}

Epilepsy is a worldwide health problem ( Medina et al ., 2005 ). Study of the prevalence of epilepsy from the developing world have shown prevalence rates of 2-25 times higher than the prevalence rate of 5-6 per 1000 in developed countries (
Radhakrishnan et al., 2000 ), Epilepsy has a special place among long term illnesses, the highest prevalence is between birth and puberty (Cowan,2008), it is potentially impending education, employment, social relationships and development of a sense of self -worth (Blume, 2003). 


\section{Childhood Focal Epilepsies}

The etiology of localization-related epilepsy is highly dependent on the age of onset. In all age groups, the etiology cannot be determined in more than half $(55 \%-89 \%)$ of all individuals with epilepsy (Banerjee et al ., 2008)

Fundamentally, there are two types of epilepsy, primary (idiopathic) generalized epilepsy and localization-related epilepsy. Partial epilepsy constitutes between $37 \%$ and $66 \%$ of childhood epilepsies, depending on the considered age-range and the modality of recruiting (Dalla , 1983) . Focal childhood epilepsies are either idiopathic or symptomatic. It was reported the important criteria for diagnosing idiopathic partial epilepsies in childhood which include absence of neurological or intellectual deficit, family hisory of epilepsy, onset after 18 months of life and seizures are usually brief with a good response to treatment (Della, 1992) . On the other hand, etiologically symptomatic partial epilepsy in children include diverse causes which may be congenital malformation, disorders of neuronal migration, , vascular, inflammatory, tumors or may occur without any obvious definable causes (David , 1993 ).

The present study was done to obtain a baseline profile of focal epilepsies in children who are of regular visit at pediatric neurology clinic or admitted to neurological Department of Queen Rania AL-Abdullah hospital for children, Focused on age of onset, associated neurological deficits electroencephalography findings, and various therapeutic aspects.

Key words: Focal Epilepsies,childhood

\section{Patients and Methods:}

Subjects included in this study were children suffering from active focal epilepsy with age above 2 years. They were attending pediatric neurology clinic or from the in-patient services of neurology Department Queen Rania Hospital for Children in Jordan. The study included children with ages ranging from 2-14 years. the following data were obtained by pediatric specialist : age, sex ,detailed of seizures type , frequency (number of seizures in the last month), type (focal or focal with 2ry generalization), aura, ictus description, post-ictus state., age at first unprovoked seizure, family history of seizure disorders, history of febrile seizures , etiological factors, socioeconomic class, history of consanguinity , additional neuroimpairment, the type of Antiepileptic drugs used (monotherapy versus polytherapy), and the degree of control on treatment. According to the degree of control on $\operatorname{AED}(\mathrm{s})$, seizures are divided into controlled if there is no seizures for $\geq 1$ year and uncontrolled if there is decrease in the frequency or change in the character of seizure from wild picture to mild presentation

Patients had their Electroencephalography (EEG ) which was Carried out at the Neurophysiologic Department. and the neuroimmaging, the results were recorded for further study .

Epilepsy was define as condition characterized by at least two or more seizures that were unprovoked by any immediate identifiable cause ( Radhakrishnan et al., 2000 ), diagnosis of epilepsy was made from the history, including the clinical description of epileptic events, neurological examination supplement with Electroencephalography findings. All patients have active epilepsy: that is all individual had at least one seizure in the last 5 year period before clinic day, regardless the anti epileptic drugs ( Radhakrishnan et al ., 2000 ).

Definitions and principles of the ILAE Commission on Classification and Terminology and the Commission on Epidemiology and Prognosis were used (Commission on Epidemiology, 1993) : (a) Generalized epilepsy, (b) partial epilepsy, which included simple or complex partial 
seizures, or secondarily generalized seizures; and (c) Unclassified seizures.

Idiopathic focal epilepsy patients were defined by age-related onset, particular clinical and Electroencephalography characteristics, and presumed genetic etiology (Commission on Epidemiology,1993) , while Remote symptomatic referred to epilepsy in the presence of a neurological abnormality, a history of brain insult, or a disorder associated with an increased risk of epilepsy that was presumed to be etiologically related to the child's epilepsy and Cryptogenic referred to epilepsy in which there was no identifiable underlying etiology and the form of epilepsy was not one of the specific idiopathic syndromes (Blume, 2003)

Socioeconomic status of families was defined as lower income if monthly earning were less than $300 \mathrm{JD}$, middle income 300$500 \mathrm{JD}$ and higher income if it was more than $1000 \mathrm{JD}$

\section{Results}

A total of 112 consecutive cases of epilepsy with partial seizure were enrolled in the study of which 59 were male (male to female ratio was 1.1:1) with ages ranged from 2 year up to 14 years. The commonest partial seizure recorded was simple partial type $52(46.4 \%)$ while simple partial with secondary generalization had 17 (16.9\%) and complex partial seizure formed $36.8 \%$.

In partial onset seizures the peak age was between 11-14 years and complex partial seizures plateau was seen between ages 6-10 years. The distribution of age for different seizure types is given in Table 1.

In complex partial the frequency of auras was $90 \%$ and the epigastric aura was the commonest In $23 \%$ of patients automatisms were detected, Automatisms were mostly oroalimentary or facial.

Demographic distribution of studied cases were shown in table II , the age of onset is found to be $32.1 \%$ before the age of 1 year
, between 1-3 years for $16 \%, 4$ to 5 years $13.3 \%$ 6-10 years $30.3 \%$ and between 11-14 years $8 \%$. The most vulnerable age for the onset of seizure ranged is less than one year. Twenty-six (23.2\%) patients reported a family history of epilepsy and $40.1 \%$ of cases have first degree of consanguinity, most of our patients $91 \%$ of low socioeconomic class.

$11.5 \%$ of cases have history of febrile seizures.

Regarding the etiology most of the cases are idiopathic $53.5 \%$ and symptomatic in 39.2 $\%$. Electroencephalography was done for 99 case $20.4 \%$ of them were normal while 57.9 $\%$ have abnormal Electroencephalography finding table 3

In most of epileptic patients at least one accessory neurological impairment, the most common were learning difficulties $35.7 \%$ cerebral palsy $29.4 \%$ and mental retardation $28.7 \%$. Table 4

Regarding response to treatment of patients receiving treatment $(22.2 \%)$ had a good seizure control, (44.5 and (33.3\%) had bad control (intractable),

Normal CT results were recorded 87 (77.8\%) and abnormal CT was recorded 25 $(22.2 \%)$. brain atrophy was the commonest $18(20 \%), 15(17 \%)$ had temporo-parietal post encephalitic 11(13\%) had cerebral infarction.

Normal MRI results were recorded in 75 cases (67\%) and abnormal results were recorded in 37 cases (33\%). (14\%) have cerebral infarction, (6\%) have cerebral hemorrhage, $12 \%$ brain malformation

\section{Discussion}

On the basis of records from pediatric neurology clinic and Department, this study has provided important baseline information on the types of focal epilepsies and associated developmental problems.

Epilepsy onset in our series occurs mainly in infancy $(32.1 \%)$, the authors attributed this to the high percentage of brain immaturity 


\section{Childhood Focal Epilepsies}

with poor ability of the brain to protect itself from abnormal electrical discharges and to the higher incidence of risk factors at that age including perinatal complications, CNS infections, head trauma and metabolic disorders

While childhood (30.3\%), a finding clearly similar to what has been repeatedly reported everywhere (Velez et al.,2006) .

As in prevalence studies of epilepsy most incidence studies find the disorder to be more common in males than females (Beilmann et al ., 1999 ), in the present study the relationship between incidence for boys and girls was 1.1: 1 which less than other figures (1.4) (Waaler et al ., 2000), while other reported incidence higher in girls than boys (male: female ratio 1:1.4 ) (Sidenvall et al ., 1993 ) .

Generalized seizure were the most frequent pattern were seen (Olafsson and Hauser , 1990 ) and in contrast with other reports in whom partial seizures were the commonest (Gallitto $\boldsymbol{G}$ et al ,. 2005 ) . Either partial or generalized seizures predominate in childhood epilepsy remains controversial (Kwong KL et al ., 2001 )

Recent several studies of new onset of seizures showed that the majority of childhood onset epilepsy is localizationrelated or partial, not generalized, as was not believed in the past. In general, it was postulated that partial epilepsies comprise slightly over $50 \%$ of all epilepsies and accounts for about $40-50 \%$ of childhood epilepsy and $90 \%$ of epilepsy in adults (Haus, 1995 ). In the present study, partial epilepsy with secondary generalization was the least frequent type of localization-related epilepsy (16.7\%) compared to simple partial epilepsy (46.4\%) and complex partial seizure was (36.6 \%).Symptomatic group represented $39.2 \%$ of our localizationrelated group of patients and this is consistent with many studies where it was formed 30\% (Braathen and Theroell, 1995). We observed that the frontal and temporal lobe epilepsies represented the most frequent types of localization-related epilepsies.

Familial occurrence of epilepsy ranged from 5-35\% in several studies (Callenbach et al ., 1998 ), it is considered a risk factors of epilepsy (Daoud et al .,2003 ) , it has long been assumed that genetic factors play a role in epilepsy, although the exact modes of inheritance remain unclear in most cases (Cowa, 2008), in present study it showed to be $23.3 \%$ of cases had family history of epilepsy, while other reported that a great majority of patients did not have family history of epilepsy (Chaves et al ., 2001 ) , it has been suggestive that, if possible, family members should undergo Electroencephalography recording, thus a careful family history should be part of routine epilepsy evaluation ( Samuel,2001 )

The importance of consanguinity and its association with epilepsy has been suggested in some studies, proved that the risk contributed to consanguinity for childhood epilepsy was not significant (Ottman, 2001 ), in our study $55.4 \%$ of cases give history of consanguinity, which is closed to other study in which $56 \%$ of cases have history of consanguinity, which signifies the importance of consanguinity as a potential risk factor for epilepsy (Asadi , 2005 ).

Febrile seizures precede epilepsy in 10 to $15 \%$ of children. Little is known about the specific types of epilepsy associated with febrile seizures ( Berg et al ., 1999 ). In the present study history of febrile seizure was presented in $11.6 \%$ of cases, most of which were simple febrile seizures which is closed to other reports in which Seventy-three children with epilepsy (13.9\%) of children with epilepsy had a history of febrile seizures (Berg et al., 1999, Waaler et al ., 2000 )

Co morbid conditions are common in children with epilepsy; some may even overshadow epilepsy (Berg et al ., 1999) , the reported prevalence of these disabilities 
in children with epilepsy varies depending on how the conditions are ascertained and defined and weather estimates are derived among incident or prevalence of epilepsy countries ( Radhakrishnan et al .,2000 ), it is well know that mental retardation, speech disorders and specific learning disorders are more common in people with epilepsy than in general population (Sillanpaa, 1992 ), in recent study $29.4 \%$ of cases are epilepsy associated with cerebral palsy which is closed to other report countries ( Radhakrishnan et al ., 2000 ) , several investigations including this report, have observed high frequencies of additional neurological deficits in children with epilepsy regard mental retardation and cerebral palsy (Waaler et al., 2000)

Although the occurrence of educational underachievement in children with epilepsy is well documented, the factors underlying this academic vulnerability have not yet been clearly identified (Adewuya et al. , 2006 ), In our study it was showed that 35.7 $\%$ of cases have learning disabilities, several epidemiologic studies have indicated that about half the children with epilepsy will have some schooling difficulty (Frank and Besag ,1995 ) . It was reported the frequent occurrence of autistic behave in children and adolescents with epilepsy (32\%) (Clarke et al ., 2005 ) · In our study the figure is less than this figure but it is closed to other report $7.1 \%$ (Waaler et al., 2000) .

A high percentage of the present study are belong to low social economic class, which may be due to the nature coverage of health insurance, but it is well known that poverty and illiteracy promote disease (Preux et al ., 2005 ) and Low socioeconomic status is associated with increased prevalence of epilepsy (Heaney et al., 2002) but it was reported that socioeconomic status is a risk factors for epilepsy in adults but not in children (Hesdorffer et al ., 2005 )

We recorded idiopathic epilepsies as a commonest etiology in $53.5 \%$ of children that is closed to other report (Freitag et al.,
2001 ), while other reported symptomatic epilepsy to be the commonest (61. \%) (Banu et al ., 2003 ) .

The primary diagnosis of epilepsy is clinical but Electroencephalography plays major role in evaluating epilepsy, recognized that normal routine Electroencephalography does not exclude the diagnosis of epilepsy, routine Electroencephalography recording in patients with epilepsy may be normal with no epileptiform activity in about $50 \%$ of cases (Flink et al ., 2002 ), in the present study , Electroencephalography were performed in $88.4 \%$ of patients of these $20.4 \%$ were normal while other reported to be $61 \%$ (Velez et al., 2006 ), abnormal Electroencephalography which is either slow background found in $8.1 \%$ of cases while epileptic activity is found in $49.5 \%$, other reported $34.4 \%$ of cases had abnormal background activity (Banu et al ., 2003 ), while others reported be abnormal in $90.3 \%$

. (Gallitto G et al ., 2005 )

It was reported that the most reliable EEG abnormalities are the focal spikes or sharp wave discharges over the frontal or temporal lobes (AL-Suliman , 1999 ). The authors postulated that the frontal and temporal foci are highly epileptogenic in greater than $85 \%$ of individuals.

Our study showed that MRI detected abnormal findings in (67\%). The incidence of abnormal MRI findings in this study correlates fairly with what had been mentioned in the literature (Abbashar and Ammar , 2007).

Once the seizure type and epilepsy syndrome have been determined, an antiepileptic drug can be appropriately selected (Sillanpaa , 1998 ) .The main objective of the treatment of children with epilepsy is to improve quality of life by achieving complete seizure control without medication side effects. Although most children become seizure free after introduction of the first antiepileptic drug (AED), a substantial proportion continue to 


\section{Childhood Focal Epilepsies}

have seizures refractory to AED treatment (M de Silva, 1996 ).

After the era of widespread of poly-therapy for treatment of epilepsy, it is now widely accepted that most of cases of newly diagnosed epilepsy in adult or children can be control with single antiepileptic drug (Reynolds\&Shorvon, 1981), Although anticonvulsant poly-therapy has been widely and traditionally used in the treatment of epilepsy, there is little evidence of its advantages over mono-therapy and in the event of failure of optimum mono-therapy, the value of poly-therapy is not yet clear (Carpay et al .,1998), mono-therapy is generally preferable to poly therapy (Bassili et al .,2002). It had been shown that monotherapy appears to be the most frequent management strategy across cases $(68.8 \%)$, which is in agreement with recommended gaudiness and recent report (Blume , 2003)

\section{Conclusion and recommendations}

The results of this study proposed the need for long-term population epidemiological outcome studies aimed to clarify the prevalence of seizure disorders. Preventive measures by raising the standard of health education system. the pattern of epilepsy in our country do not differ from that of developed countries, further population based epidemiological research is indicated to confirm the prevalence of seizure disorders in this locality Furthermore, this knowledge will facilitate early educational intervention and multidisciplinary therapeutic and rehabilitation approaches

Table I : Seizure type with age in childhood epilepsy

\begin{tabular}{||l|c|c|c|c|c|c|c|c||}
\hline \multirow{2}{*}{ Seizure type } & \multicolumn{2}{|c|}{$2-5$ years } & \multicolumn{2}{c|}{$6-10$} & \multicolumn{2}{c||}{$11-14$} & \multicolumn{2}{c|}{ Total } \\
\cline { 2 - 10 } & No & $\%$ & No & $\%$ & No & $\%$ & No & $\%$ \\
\hline 1-Simple Part & & & & & & & & \\
\hline 2-Complex part & 16 & 13.1 & 12 & 10.7 & 24 & 21.4 & 52 & 46.4 \\
\hline 3-2end gene & 12 & 10.7 & 21 & 18.8 & 10 & 8.9 & 43 & 38.4 \\
\hline Total & 4 & 3.8 & 6 & 5.4 & 7 & 6.3 & 17 & 15.1 \\
\hline
\end{tabular}


Table II: demographic distributions of studied cases

\begin{tabular}{|c|c|c|}
\hline Characters & no & $\%$ \\
\hline $\begin{array}{l}\text { Age of onset } \\
<1 \text { year }\end{array}$ & 36 & 32.1 \\
\hline $1-3$ & 18 & 16 \\
\hline $4-5$ & 15 & 13.3 \\
\hline $6-10$ & 34 & 30.3 \\
\hline $11-14$ & 9 & 8 \\
\hline $\begin{array}{l}\text { Sex } \\
\text { Male }\end{array}$ & 59 & $\mathbf{5 2 . 7}$ \\
\hline Female & 53 & 47.3 \\
\hline + History of febrile seizures & 13 & 11.6 \\
\hline Simple & 11 & 9.8 \\
\hline Complex & 2 & 1.7 \\
\hline + Consanguinity & 62 & 55.4 \\
\hline First & 45 & 40.1 \\
\hline Second & 17 & 15.1 \\
\hline + Family history of epilepsy & 26 & 23.2 \\
\hline \multicolumn{3}{|l|}{ Socioeconomic class } \\
\hline Low & 102 & 91 \\
\hline Middle & $\mathbf{1 0}$ & 9 \\
\hline $\begin{array}{l}\text { Etiology } \\
\text { Idiopathic }\end{array}$ & 60 & $\mathbf{5 3 . 5}$ \\
\hline Cryptogenic & 7 & 6.2 \\
\hline Remote symptomatic & 45 & 39.2 \\
\hline
\end{tabular}


Table III Type of EEG abnormality in partial seizure groups.

\begin{tabular}{|l|c|}
\hline \multicolumn{1}{|c|}{ EEG recorded } & percent \\
\hline Asymmetrical background & 7.9 \\
\hline Multifocal sharp waves & 9.2 \\
\hline Abnormal background with sharp wave & 8.3 \\
\hline Sharp wave alone and location : & 18.9 \\
Frontal & 4.3 \\
Temporal & 8.6 \\
Occipital & 2.9 \\
Partial & 3.1 \\
& \\
\hline Generalized slow wave & 9.6 \\
\hline Partial with secondary generalization & $4 \%$ \\
\hline Total & 57.9 \\
\hline
\end{tabular}

Table IV: neurological deficit in childhood epilepsy

\begin{tabular}{||l|c|c}
\hline \multicolumn{1}{|c|}{ Epilepsy Associated neurological deficit } & No & $\%$ \\
\hline Learning difficulties & 33 & 35.7 \\
\hline CP & 32 & 29.4 \\
\hline MR & 6 & 28.7 \\
\hline Speech disorders & 7 & 23.2 \\
\hline Development delay & 6 & 20.5 \\
\hline Visual & 1 & 6.2 \\
\hline Autistic & 23 & 5.3 \\
\hline ADHD & 40 & 5.3 \\
\hline
\end{tabular}

Reference:

Abbashar H, Ammar E (2006). The pattern and treatment of epilepsy among Sudanese epileptic patients. Emirates Medical Journal. 24:54-58.

Adewuya AO, Oseni SB, Okeniyi JA. (2006 ).School performance of Nigerian adolescents with epilepsy. Epilepsia. Feb;47(2):415-20

AL-SULAIMAN AA, ISMAIL HM. (1999).Clinical pattern of newly-diagnosed seizures in Saudia Arabia: a prospective study of 263 children. Childs Nerv Syst.;15(9):468-471

Asadi-Pooya AA (2005). Epilepsy and consanguinity in Shiraz, Iran. Eur J Paediatr Neurol.;9(6):383-6. Epub 2005 Aug 2

Banerjee PN, Hauser WA (2008) . Incidence and prevalence. In: Engel $\mathbf{J} \mathrm{Jr}$, Pedley TA, editors. Epilepsy: A Comprehensive Textbook. 2nd ed. Philadelphia,PA: Wolters Kluwer Lippincott Williams Wilkins;. p. 45-56.

Banu SH, Khan NZ, Hossain M, Jahan A, Parveen M, Rahman N, Boyd SH, Neville B. (2003 ).Profile of childhood epilepsy in Bangladesh. Dev Med Child Neurol. Jul;45(7):477-82.

Bassili A, Omar T, Zaki A, Abdel-Fattah M, Tognoni G; (2002)Egyptian-Italian Collaborative Group on Paediatric Chronic Diseases. Pattern of diagnostic and therapeutic care of childhood epilepsy in Alexandria, Egypt. Int J Qual Health Care. Aug;14(4):277-84.

Beilmann A, Napa A, Soot A, Talvik I, Talvik T. (1999 ) Prevalence of childhood epilepsy in Estonia. Epilepsia. Jul;40(7):1011-9 
Berg AT, Shinnar S, Levy SR, Testa FM (1999). Childhood-onset epilepsy with and without preceding febrile seizures. Neurology. Nov 10;53(8):1742-8.

Blume WT ( 2003 ). Diagnosis and management of epilepsy. CMAJ. Feb 18;168(4):441-8.

BRAATHEN G, THEORELL K (1995). A general hospital population of a childhood epilepsy. Acta Paediatr.;8(10):1143-1146

Callenbach PM, Geerts AT, Arts WF, van Donselaar CA, Peters AC, Stroink H, Brouwer OF (1998). Familial occurrence of epilepsy in children with newly diagnosed multiple seizures: Dutch Study of Epilepsy in Childhood. Epilepsia. Mar;39(3):331-6

Carpay HA, Arts WF, Geerts AT, Stroink H, Brouwer OF, Boudewyn Peters AC, van Donselaar CA(1998). Epilepsy in childhood: an audit of clinical practice. Arch Neurol. May;55(5):668-73.

Chaves-Sell F, Dubuisson-Schonemberg V (2001). Profile of epilepsy in a neurology clinic in Costa Rica] Rev Neurol. Sep 1-15;33(5):4113.

Clarke DF, Roberts W, Daraksan M, Dupuis A, McCabe J, Wood H, Snead OC 3rd, Weiss SK. (2005) The prevalence of autistic spectrum disorder in children surveyed in a tertiary care epilepsy clinic. Epilepsia. Dec;46(12):1970-7.

Commission on Epidemiology and Prognosis, International Leaque Against Epilepsy ( 1993

). Guidelines for epidemiologic studies on epilepsy . Epilepsia ;34:592-6.

Cowan LD. (2002) . The epidemiology of the epilepsies in children. Ment Retard Dev Disabil Res Rev.;8(3):171-81. Review

Dalla Bernardina, B.; Colamria, V.; Capovilla, G. and Bonda Valli, S. (1983): Nosological classification of epilepsies in the first three years of life. Progress in clinical and biological research (Eds.). Nistico, C.; Di-Perri, R. and Meinardi, H. Alan R. Liss, New York, pp. 165-183.

Dalla Bernardina, B.; Sgro, V.; Fontana, E.; Colamaria, V. and Selva, L. (1992) Idiopathic partial epilepsies in childhood. In advances of epielptology, :New Yor, Raven Press, pp. 173183.

Daoud AS, Batieha A, Bashtawi M, El-Shanti H. (2003) Risk factors for childhood epilepsy: a case-control study from Irbid, Jordan. Seizure. Apr;12(3):171-4.
David, R.F.; Shelafh, J.S., et al. (1993): Surgical treatment of children with medically intractable frontal or temporal lobe epilepsy. Epilepsia, 34(2):244-247

Flink R, Pedersen B, Guekht AB, Malmgren K, Michelucci R, Neville B, Pinto F, Stephani U, Ozkara C; Commission of European Affairs of the International League Against Epilepsy: Subcommission on European Guidelines. (2002 ) Guidelines for the use of Electroencephalography methodology in the diagnosis of epilepsy. International League Against Epilepsy: commission report. Commission on European Affairs: Subcommission on European Guidelines. Acta Neurol Scand. Jul;106(1):1-7. Review.

Frank M. C. Besag (1995). Epilepsy, Learning, and Behavior in Childhood. Epilepsia Jan; 36, (1,: 58-63

Freitag CM, May TW, Pfafflin M, Konig S (2001), Rating D. Incidence of epilepsies and epileptic syndromes in children and adolescents: a population-based prospective study in Germany. Epilepsia. Aug;42(8):979-85.

Gallitto G, Serra S, La Spina P, Postorino P, Lagana A, Tripodi F, Gangemi S, Calabro S, Savica R, Di Perri R, Beghi E, Musolino R (2005). Prevalence and characteristics of epilepsy in the Aeolian islands. Epilepsia. Nov; 46(11):1828-35.

HAUSER WA (1995). Epidemiology of epilepsy in children. Neurosurg Clin N Am.;6(3):419-

Heaney DC, MacDonald BK, Everitt A, Stevenson S, Leonardi GS, Wilkinson P, Sander JW (2002). Socioeconomic variation in incidence of epilepsy: prospective community based study in south east England. BMJ. Nov 2;325(7371):1013-6.

Hesdorffer DC, Tian H, Anand K, Hauser WA, Ludvigsson P, Olafsson E, Kjartansson O (2005). Socioeconomic status is a risk factor for epilepsy in Icelandic adults but not in children. Epilepsia. Aug;46(8):1297-303.

Kwong KL, Chak WK, Wong SN, So KT (.2001) Epidemiology of childhood epilepsy in a cohort of 309 Chinese children. Pediatr Neurol. Apr;24(4):276-82.

M de Silva, B MacArdle and M McGowan et al., (1996) Randomized comparative monotherapy trial of phenobarbitone, phenytoin, carbamazepine, or sodium valproate for newly 


\section{Childhood Focal Epilepsies}

diagnosed childhood epilepsy, Lancet 347, pp. 709-713

Medina MT, Duron RM, Martinez L, Osorio JR, Estrada AL, Zuniga C, Cartagena D, Collins JS, Holden KR. (2005) . Prevalence, incidence, and etiology of epilepsies in rural Honduras: the Salama Study. Epilepsia. , 46(1):124-31.

Olafsson E, Hauser WA (1999). Prevalence of epilepsy in rural Iceland: a population-based study. Epilepsia;40: 1529-34.

OTTMAN R (2001). Progress in the genetics of the partial epilepsies. Epilepsia.;42(5):24-30

Preux PM, Druet-Cabanac M. (2005) Epidemiology and aetiology of epilepsy in subSaharan Africa. Lancet Neurol. Jan;4(1):21-31. Review

Radhakrishnan K, Pandian JD, Santhoshkumar T, Thomas SV, Deetha TD, Sarma PS, Jayachandran D, Mohamed E. ( 2000 ). Prevalence, knowledge, attitude, and practice of epilepsy in Kerala, South India. Epilepsia. Aug;41(8):1027-35.
Reynolds, E.H., Shorvon, S.D. (1981) Monotherapy or polytherapy for epilepsy ? Epilepsia, 22 pp. 1-10

Samuel F. Berkovic, Ingrid E. Scheffer (2001). Genetics of the Epilepsies Epilepsia;42, (5), 1623,

Sidenvall R, Forsgren L, Blomquist HK, Heijbel J. (1993) A community-based prospective incidence study of epileptic seizures in children. Acta Paediatr. Jan;82(1):60-5. -

Sillanpaa M (1992). Epilepsy in children: prevalence, disability, and handicap. Epilepsia. May-Jun;33(3):444-9.

Sillanpaa M, Jalava M, Kaleva O, Shinnar S. (1998) .Long-term prognosis of seizures with onset in childhood. N Engl J Med;338:1715-22.

Velez A, Eslava-Cobos J ( 2006 ) . Epilepsy in Colombia: epidemiologic profile and classification of epileptic seizures and syndromes. Epilepsia. Jan;47(1):193-201.

Waaler PE, Blom BH, Skeidsvoll H, Mykletun A. (2000) . Prevalence, classification, and severity of epilepsy in children in western Norway. Epilepsia. Jul;41(7):802-10. 


\title{
الصرع البؤري الطقولي
}

\author{
و ائل هايل خريسات \\ أعصاب الأطفال مستشفى الملكة رانيا للأطفال الخدمات الطبية الملكية عمان الأردن
}

تمت هذه : الدر اسة من أجل الحصول على لمحة الصرع البؤري في الأطفال

المرضى وطرق الدراسة:

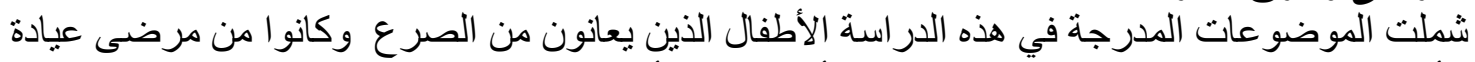

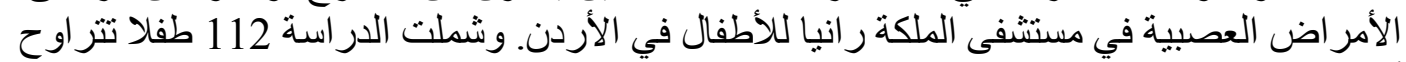

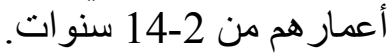

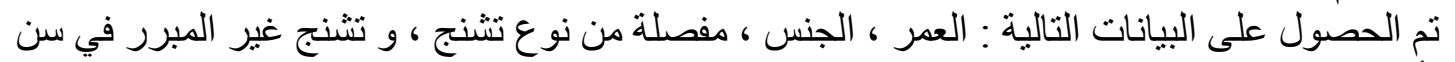

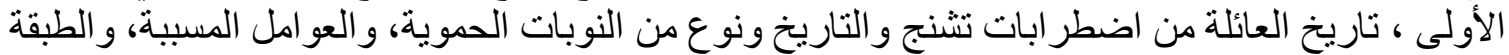

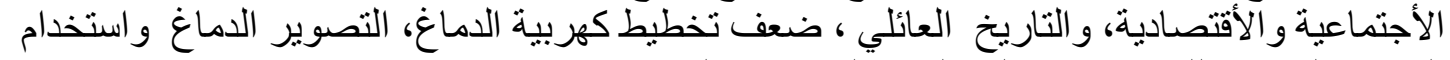

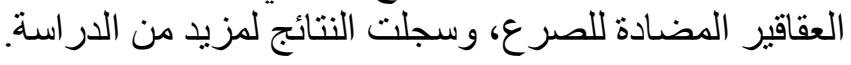

تم تسجيل 112 حالة صر ع جزئية ، 59من الذكور ـ وكان أشيع نوع النوبات الجزئية البسيطة سجلت 52 البئ

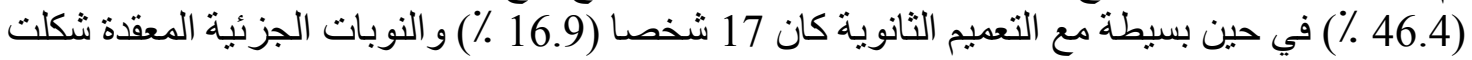

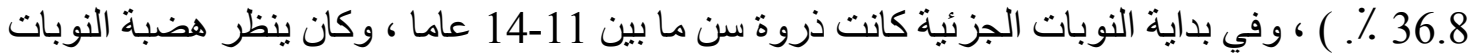

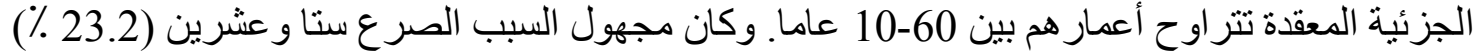

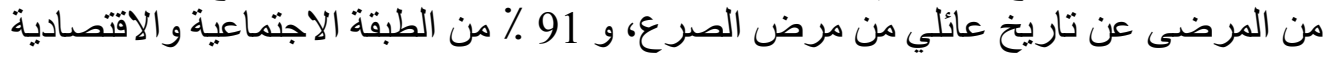

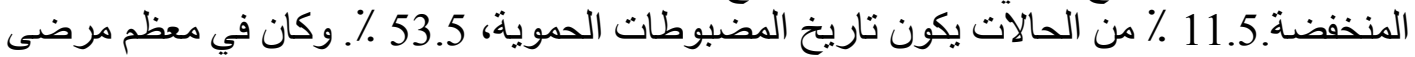
الصرع ضعف العصبية ، و أكثر ها شيو عا صعوبات في التعلم وتخطيط كهربية الدماغ العادي في 20.4 ٪ وتستخدم في علاج أحادي 68.8 \%

انتشط الصنتاج : الصرع في بلادنا لا تختلف عن تللك في البلدان المتقدة ،ويفضل المزيد من البحوث للتأكد من مدى 